\title{
ANALISIS DAMPAK LALULINTAS PEMBANGUNAN PUSAT PERBELANJAAN: STUDI KASUS PLAZA AMBARUKMO
}

\author{
Ahmad Munawar \\ Magister Sistem dan Teknik Transportasi, \\ Jurusan Teknik Sipil dan Lingkungan, F.T. U.G.M.
}

\begin{abstract}
Abstrak
Analisis dampak lalulintas merupakan bagian dari analisis mengenai dampak lingkungan, Analisis ini diperlukan pada suatu rencana pembangunan suatu pusat kegiatan, yang diperkirakan akan memberikan dampak terhadap arus lalulintas di sekitarnya. Metoda yang digunakan adalah dengan memperkirakan dampak lalulintas jika dibangun pusat kegiatan tersebut, dan usaha yang dilakukan untuk mengatasinya. Penerapan metodologi ini diuraikan dengan studi kasus analisis dampak lalulintas pembangunan Plaza Ambarrukmo di Yogyakarta. Pertama-tama dilakukan survai lalulintas, geometri di sekitarnya, serta tata bangunan plaza tersebut. Hasil analisis memberikan rekomendasi tentang perbaikan-perbaikan lingkungan Plaza Ambarrukmo tersebut, termasuk ruas-ruas jalan di sekitarnya guna menghindari kemacetan yang mungkin terjadi akibat pembangunan plaza tersebut.
\end{abstract}

Kata kunci: dampak lalulintas, pusat perbelanjaan, lingkungan

\section{Pendahuluan}

Analisis Dampak Lalu lintas (Andalalin) pada dasarnya merupakan analisis pengaruh pengembangan tata guna lahan terhadap sistem pergerakan arus lalu lintas disekitarnya, yang diakibatkan oleh bangkitan lalu lintas yang baru, lalu lintas yang beralih, dan oleh kendaraan keluar masuk dari/ke lahan tersebut. Andalalin sangat beragam, bergantung pada kondisi setempat dan kebijakan yang ada. Andalalin dapat bersifat makroskopik pada tahap pra kajian kelayakan suatu pengembangan lahan, yang perhatian utamanya lebih diarahkan pada sistem transportasi makronya, selain itu dapat juga bersifat rinci (mikroskopik). Kebijakan pengendalian dampak lalu lintas dapat berupa usaha meminimalkan dampak lalu lintas, misalnya peningkatan kapasitas jalan.

Secara umum metode Andalalin mengacu pada Analisis Mengenai Dampak Lingkungan (Amdal) dan untuk DIY mengikuti Perda 05/2004. Daerah yang dikembangkan adalah daerah yang memberikan bangkitan dan tarikan lalu lintas baru yang akan membebani lalu lintas yang ada. Rekomendasi yang diberikan dapat berupa upaya yang harus dilakukan terhadap sistem lalu lintas dan prasarana yang ada guna menghadapi tambahan beban dari 
kawasan yang akan dikembangkan. Masa kajian Andalalin diarahkan pada program peningkatan 5 atau 10 tahunan sampai masa 20 tahun ke depan dari sejak kawasan tersebut dibuka dan berfungsi sepenuhnya (sesuai dengan pentahapan pembangunan kawasan tersebut).

Menurut The Institute of Transportation Engineers (2006), ada 3 dampak yang akan ditimbulkan oleh suatu pusat kegiatan terhadap lalu lintas, yaitu kelancaran arus lalu lintas, kenyamanan pejalan kaki dan keselamatan lalu lintas. Adapun yang akan menerima dampak adalah:

1. Pengguna jalan (road user);

2. Penduduk setempat (local resident);

3. Fasilitas umum setempat (local community facilities);

4. Kegiatan perekonomian setempat (local bussiness);

5. Pengelolaan angkutan umum (public transport operators);

6. Pemerintah daerah setempat (local authority).

Besar-kecilnya dampak terhadap arus lalu lintas dipengaruhi oleh hal-hal sebagai berikut ini.

1. Bangkitan perjalanan.

2. Menarik-tidaknya suatu pusat kegiatan.

3. Tingkat kelancaran lalu lintas pada jaringan jalan yang ada.

4. Prasarana jalan di sekitar pusat kegiatan.

5. Jenis tarikan perjalanan oleh pusat kegiatan.

6. Kompetisi beberapa pusat kegiatan yang berdekatan.

\section{Metode}

Metode analisis dampak lalulintas dapat dilihat pada Gambar 1.

Analisis-analisis yang dilakukan meliputi:

a. Analisis bangkitan dan tarikan lalu lintas pada kondisi tanpa proyek: dilakukan pada masa sebelum beroperasi plaza, untuk mengetahui kondisi jaringan jalan sebelum beroperasinya pusat kegiatan plaza dan prediksi selama 10 tahun ke depan seandainya tanpa adanya proyek. Analisis ini berguna untuk membandingkan dengan kondisi setelah beroperasinya proyek. Pertama-tama, diperkirakan bangkitan dan tarikan lalu 


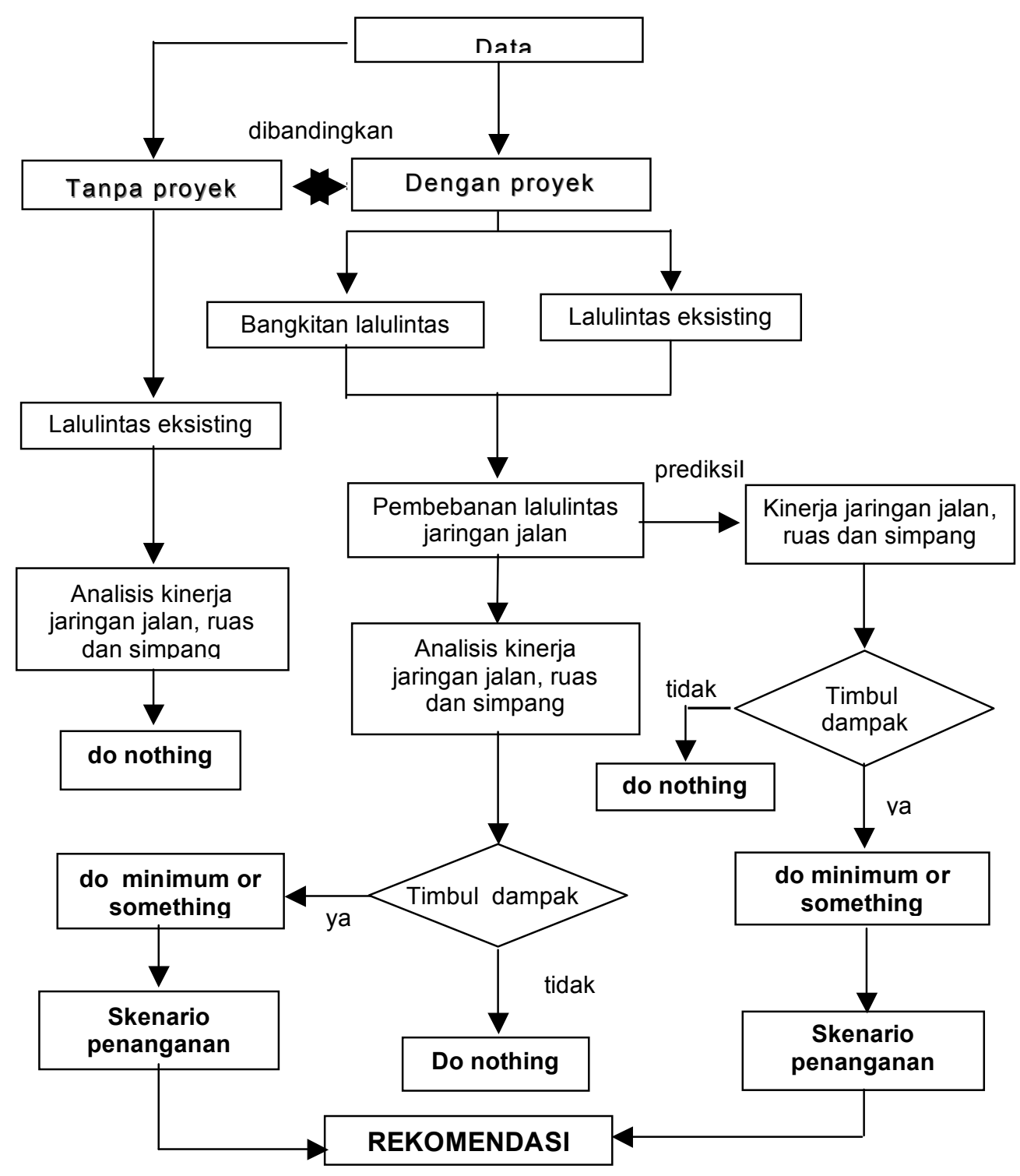

Gambar 1. Bagan Alir Metode

lintas akibat pembangunan pusat perbelanjaan yang akan memberi tambahan beban terhadap jaringan jalan di kawasan sekitarnya. Hal-hal yang dilakukan adalah :

1) menganalisis bangkitan dan tarikan lalu lintas pusat perbelanjaan dengan data pembanding pada tipikal pusat perbelanjaan yang diasumsikan sama;

2) menganalisis jangkauan wilayah pelayanan (catchment area) pusat perbelanjaan;

3) memprediksi dan menganalisis besaran dampak lalu lintas sampai 10 tahun mendatang.

4) menentukan rute jalan yang terbebani bangkitan arus lalu lintas dari pusat perbelanjaan tersebut 
5) menghitung beberapa parameter yang mempengaruhi kinerja ruas dan simpang, seperti : derajat kejenuhan, kecepatan, panjang antrian dan tundaan. Metode yang digunakan adalah metoda Manual Kapasitas Jalan Indonesia (MKJI), 1997. Hasil perhitungan dengan MKJI ini kemudian dikalibrasi untuk mendapatkan hasil perhitungan yang mendekati kondisi yang sesuai dengan keadaan di lapangan.

6) Menganalisis gangguan keselamatan lalulintas. Analisis yang dilakukan adalah mencermati akses - akses yang memiliki potensi terjadinya kecelakaan dari kendaraan yang masuk atau keluar dari jalan akses dengan lalu lintas menerus.

b. Analisis Penanganan Masalah: analisis ini diharapkan dapat memberikan solusi untuk meminimalkan dampak lalu lintas. Adapun langkah-langkah penanganan masalah adalah sebagai berikut :

1) Do nothing: tidak melakukan kegiatan pada kondisi jaringan jalan yang ada.

2) Do minimum: manajemen lalu lintas atau mengoptimalkan prasarana yang tersedia, dengan melakukan re-cycle simpang bersinyal, memasang rambu, marka dll.

3) Do something, Melaksanakan upaya peningkatan, perbaikan geometrik ruas dan simpang atau pembangunan jalan baru (interchange pada simpang).

\section{Studi Kasus: Plaza Ambarukmo}

Plaza Ambarukmo terletak di Desa Caturtunggal, Kecamatan Depok, Kabupaten Sleman, lingkungan sekitar menurut peruntukkannya dikembangkan menjadi kawasan bisnis, sesuai dengan pemanfaatan ruang di dalam RTRW sebagai kawasan perdagangan (kawasan Jalan Adi Sucipto sejak dari Jalan Solo samapi dengan Ring Road Timur). Plaza tersebut dibangun diatas tanah seluas kurang lebih $20.000 \mathrm{~m}^{2}$ dengan luas bangunan $110.719 \mathrm{~m}^{2}$ terbagi dalam 7 lantai dengan zoning ruang usaha meliputi :

> Lower Ground Floor :. Carrefour, Restaurant, Fast Food, Bakery, Play Ground, Healthcare, Equipment, Boutique Book Store, Gift Shop, Florist, DVD/VCD Rental, Banking, Travel Biro, ATM Center, Money Changer, Photo Studio, Salon Beauty, House Ware, Glassware, Bedding, Kid Fashion, Pharmacy, HP Center dan Exhibition Area;

Ground Floor : Carrefour, Restaurant, Fast Food, Bakery, Optik, Jewelleries, Watches, Women/Men Fashion, Women/Men Shoes, Bags \& Leather, Textile, Sportwear Fashion \& Shoes, Shoes Repair, Laundry, Camera Shop, dan Pharmacy; 
First Floor : Centro (Ladies Fashion), Fast Food, Café, Kids Fashion, Game Zone, Photo Studio, Game Shop, Women/Men Fashion, Women/Men Shoes, Accessories, Jewelleries, Watches, Batik, Moslem Fashion, Handycraft, Salon \& Beauty Center, Health Product, Bags \& Leather dan Exhibition Area;

Second Floor : Centro (Man Fashion), Women/Men Fashion, Women/Men Shoes, Bags \& Leather, Watches, Tailor, Salon \& Beauty Center, Sportwear Fashion \& Shoes, Golf Equipment, CD/Cassete/Store, Audio Video, Telecommunication Provider, Photo Studio, Outdoors Equipment, Music Store, Electronics, Book Store, dan Exhibition Area.

Third Floor : Management Office, Entertainment Center, Cineplex 21, Indonesian Restaurant, Oriental Restaurant, Western Restaurant, Café, Bakery, Fast Food Restaurant, Hardware Store, CD/Cassete Store dan Food Court

Dalam rangka mendukung kegiatan usaha di Plaza tersebut disediakan tempat parkir untuk kendaraan roda empat (mobil) dan roda dua (sepeda motor). Jumlah tempat parkir yang disediakan untuk parkir mobil 1047 unit dan jumlah tempat parkir untuk sepeda motor 990 unit . Lokasi Plaza Ambarrukmo dan titik-titik konflik yang mungkin terjadi dengan adanya plaza tersebut dapat dilihat pada gambar 2 .

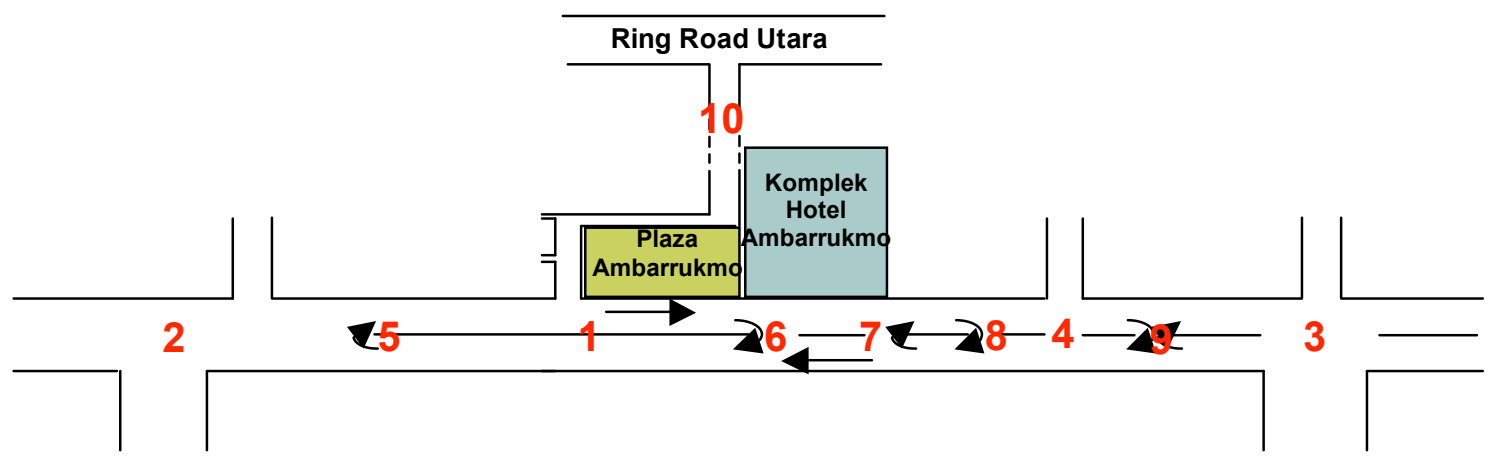

Keterangan :

1: Ruas Jalan Laksa Adi Sucipto 7 : U - Turn Ambarrukmo Timur

2: Simpang UIN

8 : U - Turn Kantor Polsek Depok Barat

3: $\quad$ Simpang Janti

9 : U - Turn Pengairan

4: Simpang Telaga Biru

10 : Rencana Jalan Akses ke Ringroad Utara

5: U - Turn Social Agency

6 : U - Turn Ambarrukmo Barat

Gambar 2. Lokasi Plaza Ambarrukmo dan Potensi Titik-titik Konflik 
Untuk mengetahui besaran arus lalulintas pada periode jam puncak maka dilaksanakan survai 6 jam yang dilaksanakan pada hari pada ruas jalan Laksda Adi Sucipto. Volume lalulintas di U - Turn didapat dari hasil survai volume lalulintas di 5 Uturn di sekitar lokasi Plaza Ambarrukmo sebagai wilayah kajian yang meliputi U-Turn Social Agency, Ambarrukmo Barat, Ambarrukmo Timur, Depan Polsek Depok Barat dan Depan Kantor yang dilaksanakan pada hari Sabtu selama 6 jam. Selain data volume lalulintas, data yang disurvai juga termasuk waktu $\mathrm{u}$ - turn untuk tiap-tiap kendaraan.

Kondisi kinerja ruas jalan Laksda Adi Sucipto mendatang tanpa pengembangan dapat dilihat pada Tabel 1 berikut ini.

Tabel 1. Hasil analisis kinerja ruas jalan Laksda Adi Sucipto periode puncak (tanpa pengembangan)

\begin{tabular}{|c|l|c|c|c|c|}
\hline Tahun & Arah Arus & $\begin{array}{c}\mathbf{Q} \\
\text { Total arus } \\
\text { lalulintas } \\
\text { (smp/jam) }\end{array}$ & $\begin{array}{c}\mathbf{C} \\
\text { Kapasitas } \\
\text { (smp/jam) }\end{array}$ & $\begin{array}{c}\text { DS=Q/C } \\
\text { Derajat } \\
\text { Kejenuhan }\end{array}$ & $\begin{array}{c}\text { Kecepatan } \\
\text { (Km/jam) }\end{array}$ \\
\hline 2011 & Barat - Tmur & 1.756 & 3.183 & 0.55 & 49,5 \\
\hline & Timur - Barat & 2.286 & 3.183 & 0.72 & 46 \\
\hline 2016 & Barat - Tmur & 2.442 & 3.183 & 0.77 & 45 \\
\hline & Timur - Barat & 3.179 & 3.183 & 0.99 & 33 \\
\hline
\end{tabular}

Plaza Ambarrukmo diasumsikan masuk dalam kategori sebagai pusat perdagangan eceran, sehingga formula empiris Hasil Studi UGM (1992) yang digunakan sesuai dengan peruntukan tersebut.

1. Jumlah mobil yg parkir

Persamaan jumlah mobil yg parkir:

103.1749 + 3.83 LAE + 0.39971 PPK

Data yang ada:

LAE $($ Luas Areal Efektif) $=469($ x $100 \mathrm{~m} 2)$;

PPK (Pendapatan per Kapita) $=2.290$ (ribu rupiah),

maka diperoleh jumlah mobil yang parkir (=VPH: Volume Parkir Harian) $=2.813$

kend/hari

2. Kebutuhan ruang parkir (KRP) mobil

$\mathrm{KRP}=\mathrm{F} 1 \times \mathrm{F} 2 \times \mathrm{VPH}$

Data yang ada::

VPH $\quad$ (Volume Parkir Harian $)=2.813$; 
$\mathrm{F} 1=\quad$ Faktor akumulasi parkir MP (mobil penumpang $)=0,24 ;$

$\mathrm{F} 2=\quad$ Faktor fluktuasi parkir $=1,1$

maka diperoleh kebutuhan ruang parkir mobil $=743$ SRP

3. Jumlah sepeda motor yg parkir

Persamaan jumlah sepeda motor yang parkir :

6174.9827 - 0.45 LAE - 2.3 PPK

(asumsi yang digunakan adalah apabila semakin tinggi pendapatan perkapita maka kepemilikan sepeda motor akan berkurang dan beralih ke mobil)

Jika diketahui : LAE $=469\left(100 \mathrm{~m}^{2}\right)$;

$\mathrm{PPK}=2.290$ (ribu rupiah),

maka diperoleh jumlah sepeda motor yang parkir $=697 \mathrm{kend} / \mathrm{hari}$

4. Kebutuhan ruang parkir (KRP) sepeda motor

$\mathrm{KRP}=\mathrm{F} 1 \times \mathrm{F} 2 \times \mathrm{VPH}$

Jika diketahui : $\mathrm{VPH}=697$;

$\mathrm{F} 1=$ Faktor akumulasi parkir $\mathrm{SM}=0,14$

F2 $=$ Faktor fluktuasi parkir $=1,1$

maka diperoleh kebutuhan ruang parkir sepeda motor $=107 \mathrm{SRP}$

Asumsi yang digunakan untuk menghitung kebutuhan parkir karyawan, adalah prosentase penggunaan kendaraan pribadi $30 \%$, prosentase pemakai mobil : motor $=$ $35 \%: 65 \%$ dan faktor peak demand 0,8 .

Kebutuhan ruang parkir mobil dengan LAT $($ Luas Area Total $)=1.107\left(\mathrm{x} 100 \mathrm{~m}^{2}\right)$ :

$\begin{array}{lll}\text { KRP mobil } & = & 0,8 \times 0,3 \times 0,35 \times(280,976+2,3399 \text { LAT }) \\ & = & 0,8 \times 0,3 \times 0,35 \times(280,976+2,3399 \times 147) \\ & = & 241 \mathrm{SRP}\end{array}$

Kebutuhan ruang parkir sepeda motor dengan LAT $=1.107\left(100 \mathrm{~m}^{2}\right)$ :

$\begin{array}{lll}\mathrm{KRP} S M & & 0,8 \times 0,3 \times 0,65 \times(280,976+2,3399 \mathrm{LAT}) \\ & = & 0,8 \times 0,3 \times 0,65 \times(280,976+2,3399 \times 147) \\ & =448 \mathrm{SRP}\end{array}$

Dari hasil hitungan di atas diperoleh total kebutuhan ruang parkir kendaraan saat ini, baik pengunjung maupun karyawan. Kebutuhan ruang parkir mobil sebanyak 984 SRP dan sepeda motor sebanyak 555 SRP. Perbandingan kebutuhan parkir mobil dengan kebutuhan parkir sepeda motor memang akan tergantung pada hitungan pendapatan perkapita. 
Semakin tinggi pendapatan perkapita, semakin banyak yang mengendarai mobil dan semakin sedikit yang mengendarai sepeda motor. Sedangkan lahan parkir yang disediakan oleh pihak pengembang untuk mobil sebanyak 1047 SRP dan motor sebanyak 990 SRP (jumlah dihitung dari gambar desain), berarti dilahan parkir yang ada sudah mencukupi. Hasil selengkapnya dari pengolahan data kebutuhan parkir kendaraan di Plaza Ambarrukmo dapat di lihat pada Tabel 2 berikut ini.

Tabel. 2. Perkiraan Kebutuhan Parkir Plaza Ambarrukmo berdasarkan luas lantai bangunan (SRP)

\begin{tabular}{|c|c|c|c|c|c|c|}
\hline \multirow{2}{*}{ Tahun } & \multicolumn{2}{|c|}{ Pengunjung } & \multicolumn{2}{c|}{ Karyawan } & \multicolumn{2}{c|}{ Total } \\
\cline { 2 - 7 } & Mobil & S.Motor & Mobil & S.Motor & Mobil & S.Motor \\
\hline 2006 & 743 & 107 & 241 & 448 & 984 & 555 \\
\hline 2011 & 851 & 50 & 241 & 448 & 1.092 & 498 \\
\hline 2016 & 1.037 & 50 & 241 & 448 & 1.278 & 498 \\
\hline
\end{tabular}

Sumber : hasil analisis

Dianjurkan agar luasan parkir dibuat fleksibel, artinya ada sebagian areal parkir yang digunakan untuk mobil, dapat dirubah menjadi areal parkir untuk sepeda motor, jika ternyata parkir sepeda motor lebih banyak dari perkiraan.

Bangkitan lalu lintas yang timbul dari parkir Plaza Ambarrukmo dihitung dengan menggunakan Formula Black (1984), diperoleh perhitungan sebagai berikut :

$$
\begin{aligned}
& \text { Bangkitan mobil } \quad \text { : Gmax }=\mathrm{g} \times \mathrm{M}=60 / 78 \times 984 \\
& =757 \mathrm{kend} / \mathrm{jam} \\
& \text { Bangkitan Sepeda Motor : Gmax }=\mathrm{g} \text { x } \mathrm{M}=60 / 96 \times 555 \\
& =347 \mathrm{kend} / \mathrm{jam}
\end{aligned}
$$

Hasil perkiraan besarnya bangkitan lalu lintas Plaza Ambarrukmo sampai dengan tahun 2016 dapat di lihat pada tabel 3 di bawah ini.

Tabel 3. Perkiraan Besarnya Bangkitan Lalu Lintas Plaza Ambarrukmo

\begin{tabular}{|c|c|c|}
\hline Tahun & Mobil (kend/jam) & Sepeda Motor (kend/jam) \\
\hline 2006 & 757 & 347 \\
\hline 2011 & 840 & 311 \\
\hline 2016 & 983 & 311 \\
\hline
\end{tabular}

Kondisi kinerja ruas jalan Laksda Adi Sucipto mendatang dengan pengembangan serta perbandingannya kalau tanpa pengembangan dapat dilihat pada tabel 4 dan 5 berikut ini. 
Tabel 4. Hasil analisis kinerja ruas jalan Laksda Adi Sucipto periode puncak (dengan pengembangan)

\begin{tabular}{|c|c|c|c|c|c|}
\hline Tahun & Arah Arus & $\begin{array}{c}\mathbf{Q} \\
\text { Total arus } \\
\text { (smp/jam) }\end{array}$ & $\begin{array}{c}\mathbf{C} \\
\text { Kapasitas } \\
\text { (smp/jam) }\end{array}$ & $\begin{array}{c}\text { DS=Q/C } \\
\text { Derajat } \\
\text { Kejenuhan }\end{array}$ & $\begin{array}{c}\text { Kecepatan } \\
\text { (Km/jam) }\end{array}$ \\
\hline 2006 & Barat - Tmur & 2041 & 3.183 & 0,64 & 49 \\
\hline & Timur - Barat & 2146 & 3.183 & 0,67 & 47 \\
\hline 2011 & Barat - Tmur & 2615 & 3.183 & 0,82 & 43 \\
\hline & Timur - Barat & 2851 & 3.183 & 0,90 & 40 \\
\hline 2016 & Barat - Tmur & 3444 & 3.183 & 1,08 & 25 \\
\hline & Timur - Barat & 3849 & 3.183 & 1,21 & 20 \\
\hline
\end{tabular}

Tabel 5. Perbandingan kinerja ruas jalan Laksda Adi Sucipto periode puncak tanpa dan dengan pengembangan

\begin{tabular}{|c|c|c|c|c|c|c|}
\hline Kondisi & Thn & Arah Arus & $\begin{array}{c}\mathbf{Q} \\
\text { Total arus } \\
\text { (smp/jam) }\end{array}$ & $\begin{array}{c}\mathrm{C} \\
\text { Kapasitas } \\
\text { (smp/jam) }\end{array}$ & $\begin{array}{c}\mathrm{DS}=\mathrm{Q} / \mathrm{C} \\
\text { Derajat } \\
\text { Kejenuhan }\end{array}$ & $\begin{array}{c}\text { Kecepatan } \\
\text { (Km/jam) }\end{array}$ \\
\hline \multirow{6}{*}{$\begin{array}{c}\text { Tanpa } \\
\text { Pengem- } \\
\text { bangan }\end{array}$} & 2006 & Barat - Tmur & 1262 & 3,183 & 0,40 & 52 \\
\hline & & Timur - Barat & 1644 & 3,183 & 0,52 & 50 \\
\hline & 2011 & Barat - Tmur & 1,756 & 3,183 & 0,55 & 49,5 \\
\hline & & Timur - Barat & 2,286 & 3,183 & 0,72 & 46 \\
\hline & 2016 & Barat - Tmur & 2,442 & 3,183 & $0 ., 7$ & 45 \\
\hline & & Timur - Barat & 3,179 & 3,183 & 0,99 & 33 \\
\hline \multirow{6}{*}{$\begin{array}{c}\text { Dengan } \\
\text { Pengem- } \\
\text { bangan }\end{array}$} & 2006 & Barat - Timur & 2041 & 3.183 & 0,64 & 49 \\
\hline & & Timur - Barat & 2146 & 3.183 & 0,67 & 47 \\
\hline & 2011 & Barat - Tmur & 2615 & 3.183 & 0,82 & 43 \\
\hline & & Timur - Barat & 2851 & 3.183 & 0,90 & 40 \\
\hline & 2016 & Barat - Tmur & 3444 & 3.183 & 1,08 & 25 \\
\hline & & Timur - Barat & 3849 & 3.183 & 1,21 & 20 \\
\hline
\end{tabular}

Terlihat bahwa jika tidak dilakukan perbaikan, maka derajat kejenuhan pada tahun 2016 sudah melampaui 1. Untuk itu, perlu pengurangan hambatan samping dengan pengurangan tempat U-turn.

Sedangkan untuk simpang, analisis simpang UIN dan simpang Janti tanpa pengembangan dibandingkan dengan adanya pengembanganm dapat dilihat pada tabel 6 dan 7 di bawah ini.

Akibat pengembangan Plaza Ambarrukmo maka derajat kejenuhan untuk masing-masing lengan simpang di simpang UIN menjadi kurang merata sehingga perlu dilakukan pengaturan ulang simpang bersinyal di Simpang UIN menjadi seperti tabel 7 berikut ini. Sedangkan untuk simpang Janti, tidak diperlukan adanya suatu perbaikan. 
Tabel 6. Perbandingan kinerja simpang periode puncak tanpa dan dengan pengembangan tahun 2006

\begin{tabular}{|c|c|c|c|c|c|}
\hline Kondisi & Simpang & $\begin{array}{c}\text { DS } \\
\text { rata- } \\
\text { rata }\end{array}$ & $\begin{array}{c}\text { Panjang } \\
\text { Antrian } \\
\text { rata-rata } \\
\text { (m) }\end{array}$ & $\begin{array}{c}\text { Terhenti } \\
\text { rata-rata } \\
\text { (stop/smp) }\end{array}$ & $\begin{array}{c}\text { Tundaan } \\
\text { Rata-rata } \\
\text { (det/smp) }\end{array}$ \\
\hline $\begin{array}{c}\text { Tanpa } \\
\text { Pengembangan }\end{array}$ & UIN & 0,64 & 84,75 & 0,69 & 28,76 \\
\hline $\begin{array}{c}\text { Dengan } \\
\text { Pengembangan }\end{array}$ & UIN & 0,54 & 54,50 & 0,58 & 17,76 \\
\hline
\end{tabular}

Tabel 7. Pengaturan waktu lampu lalulintas S-3 UIN

\begin{tabular}{|c|c|c|c|c|c|}
\hline \multirow{2}{*}{$\begin{array}{c}\text { Fase } \\
\text { Pendekat }\end{array}$} & \multicolumn{4}{|c|}{ Waktu (detik) } & \multirow{2}{*}{$\begin{array}{l}\text { Siklus } \\
\text { (detik) }\end{array}$} \\
\hline & Merah & Hijau & Kuning & All red & \\
\hline Fase 1 - Timur & 54 & 32 & 3 & 1,5 & \multirow{3}{*}{90,5} \\
\hline Fase 2 - Selatan & 68 & 18 & 3 & 1,5 & \\
\hline Fase 3 - Barat & 59 & 27 & 3 & 1,5 & \\
\hline
\end{tabular}

\section{Kesimpulan dan Saran}

Berdasarkan kajian dan analisis hasil survai lapangan diperoleh kesimpulan bahwa diperlukan suatu perubahan/pengaturan guna menghilangkan dampak lalulintas akibat pembangunan Plaza Ambarukmo. Saran mengenai perubahan/pengaturan tersebut diuraikan sebagai berikut ini (lihat gambar 2).

1. Penggeseran pintu barat Hotel Ambarrukmo ke Timur sebagai akses keluar Plaza Ambarrukmo melalui Jl. Adisucipto

2. Penutupan U-turn Hotel Ambarrukmo Timur

3. Pintu timur Hotel Ambarrukmo sebagai akses keluar masuk Hotel Ambarrukmo

4. Area parkir sudah mencukupi, hanya perlu dibuat suatu area yang fleksibel, dapat digunakan untuk parkir mobil, tetapi juga dapat dirubah menjadi tempat parkir sepeda motor.

5. Sirkulasi taxi melalui pintu utama Plaza sebelahTimur

6. Parkir taxi berada di sebelah timur gedung Plaza Ambarrukmo

7. Pengubahan arus menuju pasar Ambarrukmo menjadi searah khusus mobil pada jam 09.00-22.00 
8. Arus kendaraan masuk Plaza Ambarrukmo dari arah Timur melewati U-turn Social Agency

9. Peletakan halte bus patas di sebelah Timur pintu masuk Plaza Ambarrukmo

10. Perubahan waktu siklus dan waktu hijau simpang bersinyal UIN.

\section{Daftar Pustaka}

1. Black, J.A., Blunden, W.R. (1984), The Land Use/Transport System, Pergamon Pers, Australia

2. Institute of Transportation Engineers (2006), Traffic Impact Study Guidelines: Transportation Impact Analysis for Site Development, I.T.E., Washington D.C., U.S.A.

3. Pemerintah Propinsi DIY (2004), Perda 05/2004 tentang Penyelenggaraan Lalu Lintas Jalan di Wilayah Propinsi DIY

4. UGM LPM (1992), Studi Kriteria Perancangan dan Kebutuhan Ruang Parkir pada Pusat-pusat Kegiatan (Off Street Parking), UGM, Yogyakarta 